Article

\title{
Evaluation of Microstructures and Mechanical Properties of Sn-10Sb-Ni Lead-Free Solder Alloys with Small Amount of Ni Using Miniature Size Specimens
}

\author{
Tatsuya Kobayashi *(D) and Ikuo Shohji \\ Graduate School of Science and Technology, Gunma University, Kiryu 376-8515, Japan; shohji@gunma-u.ac.jp \\ * Correspondence: kobayashi.t@gunma-u.ac.jp; Tel.: +81-277-30-1562
}

Received: 8 November 2019; Accepted: 12 December 2019; Published: 14 December 2019

\begin{abstract}
Sn-Sb-Ni solder alloy is expected to be used as a die-attach material for a next-generation power semiconductors in power module. The aim of this paper is to investigate the effects of the $\mathrm{Ni}$ content on microstructures, tensile, and fatigue properties of Sn-10Sb-xNi $(x=0.05,0.10,0.25,0.50)$ (mass\%) lead-free solder alloys using miniature size specimens. The $\mathrm{Sn}-10 \mathrm{Sb}-\mathrm{Ni}$ solder alloys have the microstructure in which $\mathrm{Sb}-\mathrm{Sn}$ and $\mathrm{Ni}-\mathrm{Sb}$ compounds are dispersed in the $\beta$-Sn matrix. As the $\mathrm{Sb}$ and Ni content increases, $\mathrm{Sb}-\mathrm{Sn}$ and Ni-Sb compounds are coarsened, respectively. The effect of the $\mathrm{Ni}$ content on tensile properties of the alloy is slight at $25^{\circ} \mathrm{C}$. At $150{ }^{\circ} \mathrm{C}$ and $200{ }^{\circ} \mathrm{C}, 0.1 \%$ proof stress and tensile strength increase gradually with the $\mathrm{Ni}$ content increases, and saturate at the $\mathrm{Ni}$ amount over 0.25 mass $\%$. According to the fatigue test at $200^{\circ} \mathrm{C}$, the fatigue properties of Sn-10Sb-Ni with $0.10-0.25$ mass \% Ni are better than that of the Sn-10Sb. From the experimental results, Sn-10Sb-Ni with $0.10-0.25$ mass $\%$ Ni have superior mechanical properties.
\end{abstract}

Keywords: solder alloy; antimony; nickel; microstructure; mechanical properties; miniature size specimen

\section{Introduction}

Power semiconductors are the key devices which control, convert, and supply electric power. They are used in the various fields such as automobiles, railway cars, machining tools, air conditioners, laptop computers, and so on to save energy. Si has typically been used as the material of the power semiconductors. Recently, next-generation power semiconductors such as $\mathrm{SiC}$ and $\mathrm{GaN}$ have been developed [1-3]. The next-generation power semiconductors make power electronics devices possible to operate at higher power levels and under high temperature environment $[4,5]$. On the other hand, it is essential for the practical use of the power electronics devices using the power semiconductors that power module components be withstood high heat environment. In particular, a die-attach material used between the power semiconductors and an insulated substrate such as $\mathrm{Al}_{2} \mathrm{O}_{3}$ and $\mathrm{AlN}$ requires both good tensile properties and high fatigue resistance [6,7]. In the present, $\mathrm{Pb}$-rich solder alloys which is over 85 mass $\% \mathrm{~Pb}$ for high temperature environment are mainly used as the die-attach material despite $\mathrm{Pb}$ being toxic [8]. This is because high-temperature lead-free solder alloys have not been yet designated by the EU-RoHS directive. Therefore, the research and development of such solder alloys is required.

It is possible that the $\mathrm{Sn}-\mathrm{Sb}$ solder alloys which have highest melting temperature range among existing lead-free solder alloys, are able to replace the $\mathrm{Pb}$-rich solder alloys [7-14]. It has been reported that the $\mathrm{Sn}-\mathrm{Sb}$ solder alloys have low electric resistivity and good mechanical properties $[7,15]$. However, in order to apply the Sn-Sb to the next-generation power semiconductors, it is necessary to further improve the tensile and fatigue properties in high temperature environment. Therefore, we focused 
on the $\mathrm{Sn}-\mathrm{Sb}$ with $\mathrm{Ni}$ minor addition to further improve these properties. We have already reported that $\mathrm{Sn}-5 \mathrm{Sb}-\mathrm{Ni}$ with $0.05-0.10$ mass \% Ni have superior fatigue properties to $\mathrm{Sn}-5 \mathrm{Sb}$ (mass \%) in the temperature range from $25^{\circ} \mathrm{C}$ to $200{ }^{\circ} \mathrm{C}$ [16]. In addition, it has been reported that the high concentration of $\mathrm{Sb}$ in the $\mathrm{Sn}-\mathrm{Sb}$ solder alloys can increase mechanical strength [17-19]. In particular, Sn-10Sb (mass\%) has been selected as another candidate together with the Sn-5Sb for previous studies [10,12,15,18].

The aim of this study was to investigate the effects of the Ni content on microstructures, tensile and fatigue properties of Sn-10Sb-Ni with $0.05-0.50$ mass\% Ni using miniature size specimens.

\section{Materials and Methods}

The ingots of Sn-10Sb-xNi ( $x=0.05,0.10,0.25,0.50)$ and Sn-10Sb solder alloys were prepared. On the basis of the differential scanning calorimetry (DSC) (DSC6200, Hitachi High-Tech Science, Inc., Tokyo, Japan) measurement result, the melting finish temperature of these solder alloys was estimated to be $247^{\circ} \mathrm{C}$ for $\mathrm{Sn}-10 \mathrm{Sb}, 247^{\circ} \mathrm{C}$ for $\mathrm{Sn}-10 \mathrm{Sb}-0.05 \mathrm{Ni}$, and $246{ }^{\circ} \mathrm{C}$ for $\mathrm{Sn}-10 \mathrm{Sb}-0.50 \mathrm{Ni}$. Therefore, these solders can be applied to high temperature applications with operating temperature up to $200{ }^{\circ} \mathrm{C}$.

Miniature size specimens were made by casting from the ingots. First, a solder wire with $1.2 \mathrm{~mm}$ diameter was fabricated by drawing each ingot. Next, the solder wire inserted in the metal mold which made of aluminum alloy for making miniature size specimen [20]. Then they were put on a hot plate and the solder wire was pressed by the metal mold at casting temperature. Maximum casting temperature which was measured with a thermocouple attached to the surface of the metal mold was $264{ }^{\circ} \mathrm{C}$ for all solder alloys. Then the metal mold included the molten solder alloy was moved to a stainless plate for cooling. Maximum cooling rate was $3.6^{\circ} \mathrm{C} / \mathrm{s}$ on the stainless plate for the all solder alloys. Finally, a solder specimen was removed from the metal mold.

Figure 1 shows appearance of the miniature size specimen. The specimen gage length and diameter are $2.0 \mathrm{~mm}$ and $0.50 \mathrm{~mm}$, respectively. The specimens were used for microstructure observation and mechanical properties test.

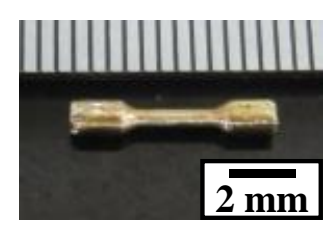

Figure 1. Appearance of miniature size specimen of solder alloy.

To observe the microstructures of miniature size specimens, cross-sectional polishing was conducted. The cross-sections of the specimens embedded in resin were polished by waterproof abrasive papers. Then, finish polishing was performed a using $1 \mu \mathrm{m}$ diameter alumina powder. The microstructures of the cross-sections of the gauge regions were observed with an optical microscope and an electron probe X-ray microanalyzer (EPMA) (EPMA-1610, Shimadzu Corp., Kyoto, Japan). Moreover, the crystal orientations of the cross-sections of the gauge regions were investigated by a field emission scanning electron microscope (FE-SEM) (S-4300SE, Hitachi High-Tech Science, Inc., Tokyo, Japan) equipped with an electron back scattering diffraction (EBSD) (TSL MSC-2200, TexSEM Laboratories, Inc., Provo, UT, USA) system.

Table 1 shows the conditions of tensile test. The tests using the miniature size specimens were performed with a displacement controlled mechanical test system (LMH207-10, Saginomiya Seisakusho, Inc., Tokyo, Japan). The tests were conducted with five specimens per condition. After the tests, the appearance and fracture surface of specimens were observed with the EPMA.

Table 1. Conditions of tensile test.

\begin{tabular}{cc}
\hline Temperature $\left({ }^{\circ} \mathbf{C}\right)$ & Strain Rate $\left(\mathbf{s}^{-\mathbf{1}}\right)$ \\
\hline $25,150,200$ & $2.0 \times 10^{-1}$ \\
\hline
\end{tabular}


Table 2 shows the conditions of fatigue test. The tests using the miniature size specimens were performed with the same equipment as the tensile tests. In each test, the continuous strain cycling of symmetrical triangle wave with a strain rate of $2.0 \times 10^{-3} \mathrm{~s}^{-1}$ were conducted. In this study, the number of cycles to failure was defined as when the maximum load on the specimen dropped to $80 \%$. After the tests, the crystal orientations and microstructures of the gauge regions were investigated by the FE-SEM equipped with the EBSD system.

Table 2. Conditions of fatigue test.

\begin{tabular}{ccc}
\hline Temperature $\left({ }^{\circ} \mathbf{C}\right)$ & Strain Rate $\left(\mathbf{s}^{-\mathbf{1}}\right)$ & Total Strain Range (\%) \\
\hline $25,150,200$ & $2.0 \times 10^{-3}$ & $0.4-2.0$ \\
\hline
\end{tabular}

\section{Results and Discussion}

\subsection{Microstructure Observation}

Figure 2 shows the optical microscopy (OM) image of the cross-sectional view of as-cast $\mathrm{Sn}-10 \mathrm{Sb}$ specimen, the corresponding EPMA mapping analysis and the magnified backscattered electron (BSE) image. In the BSE image and its EPMA mapping analysis result, the two colors of dark-gray and bright-gray were observed and identified as $\mathrm{Sn}$ and $\mathrm{Sn}-\mathrm{Sb}$ phases, respectively. Moreover, the distribution of block-shape particles with dozens of micrometers in size, was observed in the $\mathrm{OM}$ image. The particles were identified as $\mathrm{Sn}-\mathrm{Sb}$ phases by EPMA mapping analysis.

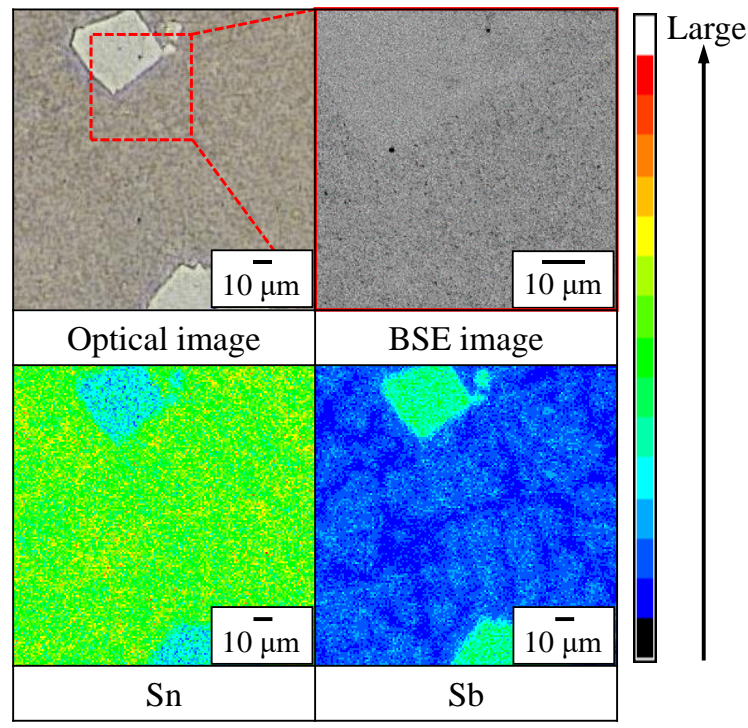

Figure 2. Optical microscopy (OM) image of microstructures of Sn-10Sb specimen, corresponding electron probe $\mathrm{X}$-ray microanalyzer (EPMA) mapping analysis result and magnified backscattered electron (BSE) image.

Figure 3 shows the Sn-Sb binary equilibrium phase diagram that was created by thermodynamic calculation analysis (Thermo-Calc 2017a, Thermo-Calc Software Inc., McMurray, PA, USA). From the EPMA mapping analysis result and the diagram, the dark-gray phases in the BSE image were inferred to the $\beta$-Sn, and the bright-gray phases in the BSE image and the block-shape particles in the OM image are both inferred to the Sb-Sn phases. It has been reported that increasing Sb contents in $\mathrm{Sn}-\mathrm{Sb}$ alloys causes the formation of coarsened Sb-Sn compounds $[15,18]$. Therefore, it was found that the Sn-10Sb has the microstructure in which fine and coarsened $\mathrm{Sb}-\mathrm{Sn}$ compounds are dispersed in the $\beta$-Sn matrix. 


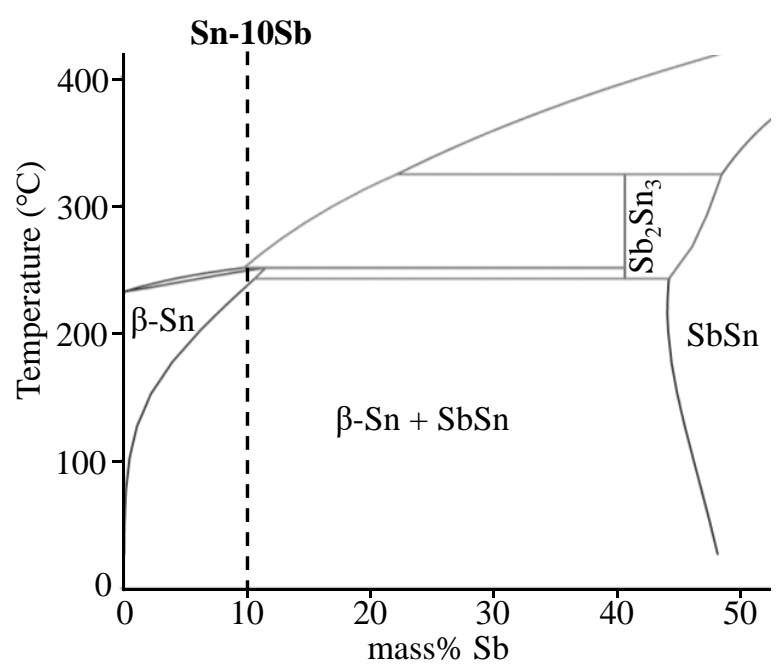

Figure 3. Sn-Sb binary equilibrium diagram [16].

Figure 4 shows the OM image of the cross-sectional view of as-cast $\mathrm{Sn}-10 \mathrm{Sb}-0.50 \mathrm{Ni}$ specimen, corresponding EPMA mapping analysis result and magnified BSE image. In the BSE image and the EPMA mapping analysis result, dark-gray, bright-gray and black phases were observed and identified as $\mathrm{Sn}, \mathrm{Sn}-\mathrm{Sb}$, and Ni-Sb phases, respectively. Moreover, in the OM image, block-shape particles were observed as well as the $\mathrm{Sn}-10 \mathrm{Sb}$, and identified as $\mathrm{Sn}-\mathrm{Sb}$ phases by EPMA.

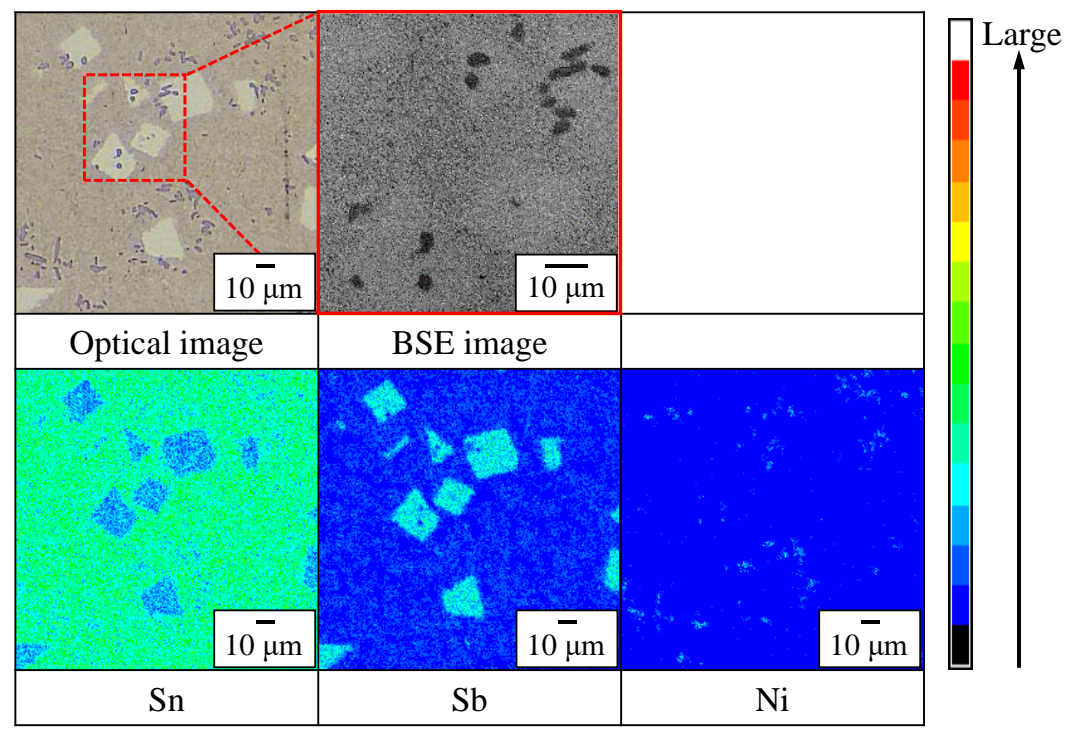

Figure 4. OM image of microstructures of Sn-10Sb-0.50Ni specimen, corresponding EPMA mapping analysis result and magnified BSE image.

Figure 5 shows the $\mathrm{Sn}-\mathrm{Sb}-\mathrm{Ni}$ ternary equilibrium phase diagram at $25^{\circ} \mathrm{C}$. The composition point of $\mathrm{Sn}-10 \mathrm{Sb}-0.50 \mathrm{Ni}$ is also plotted in the diagram. From the EPMA mapping analysis result and the diagram, the dark-gray, bright-gray, and black phases in the BSE image were inferred to be the $\beta-\mathrm{Sn}, \mathrm{SbSn}$, and NiSb phases, respectively. Furthermore, the block-shape particles in the OM image were deduced to be the SbSn phases. Therefore, it was found that the Sn-10Sb-Ni solder alloys with 0.05-0.50 mass\% Ni have the microstructure in which fine and coarsened Sb-Sn compounds and Ni-Sb compounds are dispersed in the $\beta$-Sn matrix. 


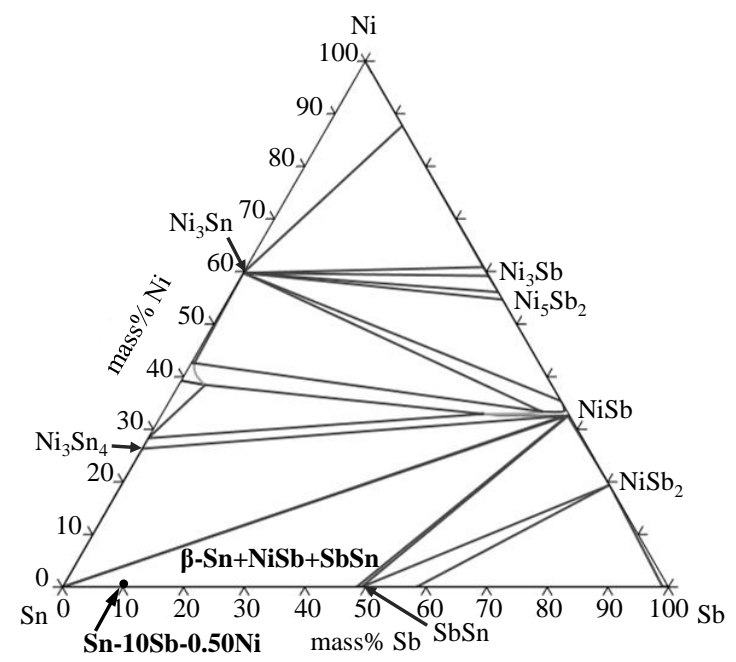

Figure 5. Sn-Sb-Ni ternary equilibrium phase diagram at $25^{\circ} \mathrm{C}$, reprinted with permission from [16], copyright The Japan Institute of Metals and Materials.

Figure 6 shows the OM images of the cross-sectional views of the miniature size specimens of $\mathrm{Sn}-10 \mathrm{Sb}$ and Sn-10Sb-Ni with 0.05-0.50 mass\%, and included that of Sn-5Sb [16] for comparison. As can be seen in the images, increasing the amount of $\mathrm{Sb}$ in the solder alloy coarsens $\mathrm{Sn}-\mathrm{Sb}$ compounds. Moreover, increasing the amount of $\mathrm{Ni}$ in the solder alloy increases and coarsens $\mathrm{Ni}-\mathrm{Sb}$ compounds.

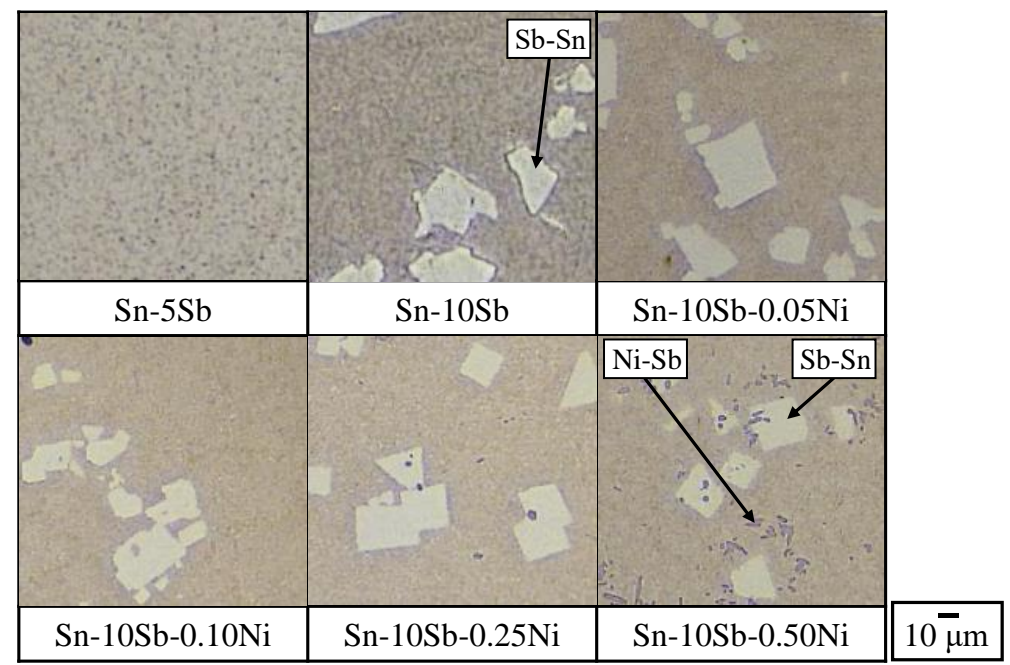

Figure 6. OM images of microstructures of Sn-5Sb, Sn-10Sb, and Sn-10Sb-Ni specimens.

Figure 7 shows the inverse pole figure (IPF) maps of the cross-sectional views of the miniature size specimens of Sn-10Sb and Sn-10Sb-Ni with $0.05-0.50$ mass $\%$ Ni that were analyzed by the EBSD system. In this study, the longitudinal direction of the specimen was set to the rolling direction (RD) in the material coordinate system used in the EBSD system. In these images, different $\mathrm{Sn}$ grain orientations in the specimens are indicated by different colors. It was found that the specimen of Sn-10Sb consists of a single grain or a few grains, and specimens of Sn-10Sb-Ni consist of several grains. 


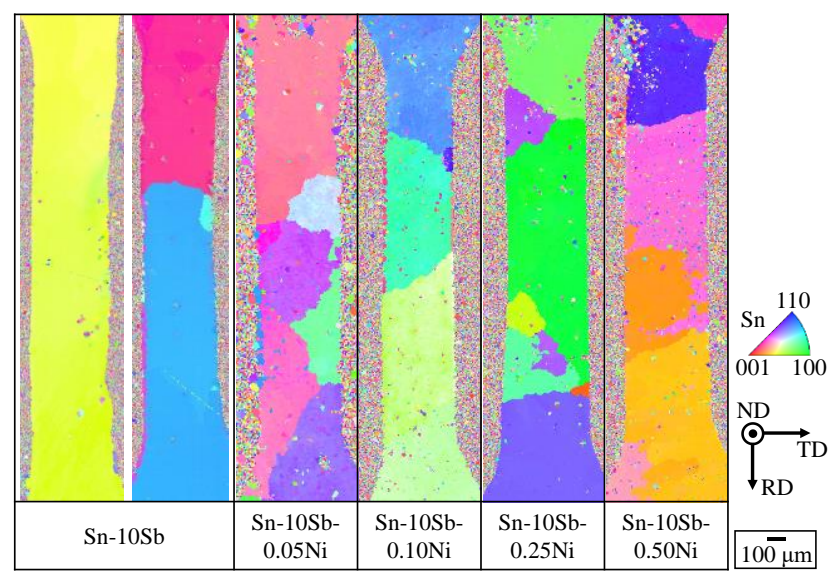

Figure 7. Inverse pole figure (IPF) maps of initial microstructures of Sn-10Sb and Sn-10Sb-Ni specimens.

\subsection{Tensile Properties and Fracture Modes}

Figure 8 shows the measurement results of the tensile properties which are $0.1 \%$ proof stress, tensile strength and elongation of Sn-10Sb-Ni with $0.05-0.50$ mass $\%$ Ni obtained by tensile test. These graphs contain results of $\mathrm{Sn}-10 \mathrm{Sb}$ for comparison. In the figure, the effects of the Ni content on the tensile properties was slight at $25^{\circ} \mathrm{C}$. We have reported that as the amount of Ni increases in Sn-5Sb-Ni with $0.05-0.50$ mass $\%$, the $0.1 \%$ proof stress and the tensile strength increase, and the elongation decreases at $25^{\circ} \mathrm{C}$ [17]. This is because the dispersion strengthening is caused by Ni-Sb compounds. In this study, it seems that the tensile properties of the Sn-10Sb-Ni are largely influenced by the dispersion of the coarsened Sb-Sn compounds which do not exist in the Sn-5Sb-Ni. At $150{ }^{\circ} \mathrm{C}$ and $200^{\circ} \mathrm{C}$, the $0.1 \%$ proof stress and the tensile strength increased gradually with increasing the Ni content. However, they saturated at a Ni amount of 0.25 mass $\%$ or more. On the other hand, the elongation increased and decreased with inconsistent behavior regardless of the Ni content. According to the effects of temperature on the tensile properties, there is a tendency for the $0.1 \%$ proof stress and tensile strength to decrease as the temperature increases, but the elongation has a small effect.

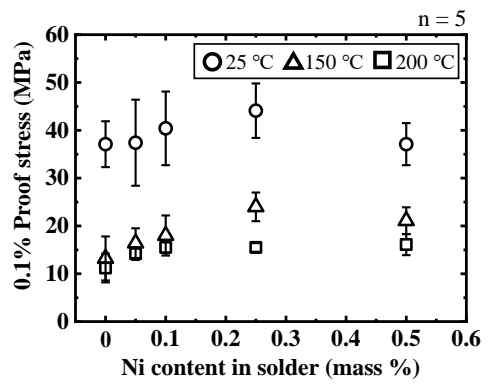

(a)

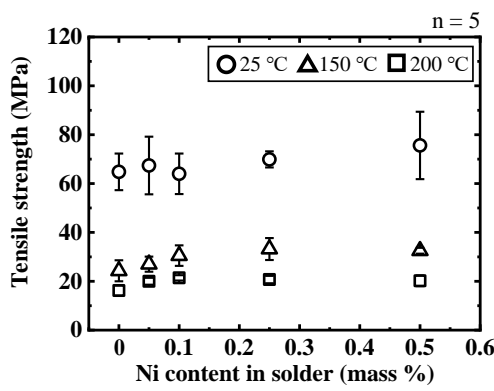

(b)

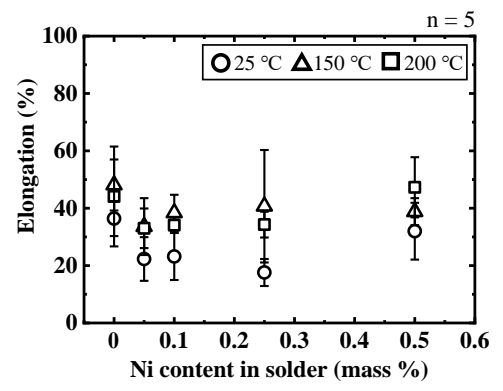

(c)

Figure 8. Tensile properties of Sn-10Sb and Sn-10Sb-Ni with $0.05-0.50$ mass $\%$ Ni. (a) $0.1 \%$ proof stress, (b) Tensile strength, and (c) Elongation. 
Figure 9 shows the volume fractions of each phase in the Sn-10Sb, Sn-10Sb-0.10Ni, and $\mathrm{Sn}-10 \mathrm{Sb}-0.50 \mathrm{Ni}$ calculated by the thermodynamic calculation analysis. In the figure, the ratio of $\mathrm{Sb}-\mathrm{Sn}$ phases decreases, that of $\beta$-Sn phases increases and that of $\mathrm{Ni}-\mathrm{Sb}$ phases remains constant with an increase in temperature. Therefore, the reason why the $0.1 \%$ proof stress and tensile strength are increased by increasing the Ni content at high temperature is that the Sb-Sn compounds are decomposed and the dispersed $\mathrm{Ni}-\mathrm{Sb}$ compounds have a significant effect.

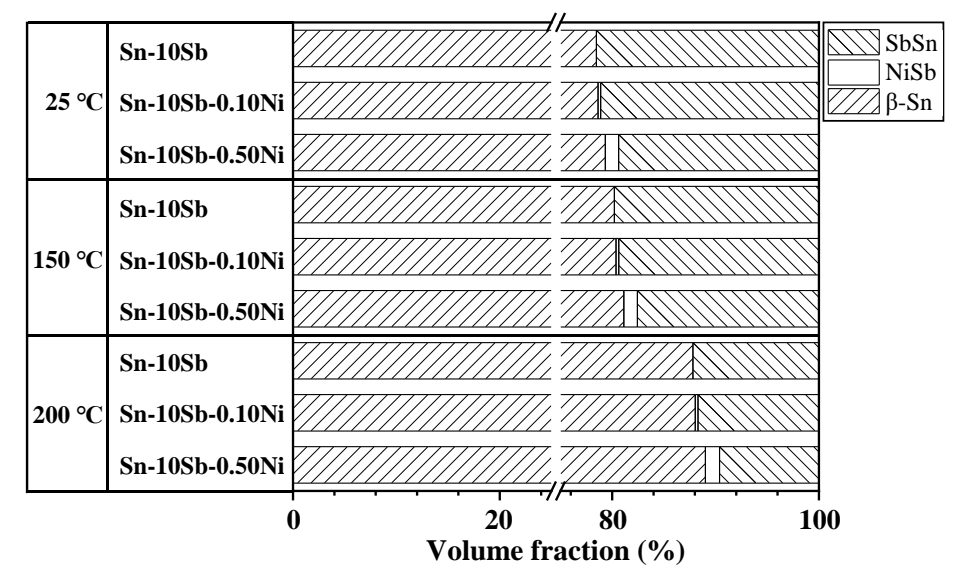

Figure 9. Volume fraction of $\beta-\mathrm{Sn}, \mathrm{Ni}-\mathrm{Sb}$, and $\mathrm{Sb}-\mathrm{Sn}$ phases in $\mathrm{Sn}-10 \mathrm{Sb}, \mathrm{Sn}-10 \mathrm{Sb}-0.10 \mathrm{Ni}$, and $\mathrm{Sn}-10 \mathrm{Sb}-0.50 \mathrm{Ni}$ solder alloys by thermodynamic calculation analysis.

Figure 10 shows the secondary electron (SE) images of fractured specimens after the tests. In the $\mathrm{Sn}-10 \mathrm{Sb}$, fractured specimens exhibited chisel-point fracture. The fracture surface was shaped like knife-edge and formed some dimples. This means that ductile fractures occurred in the Sn-10Sb specimens. It has known that the slip system of $\beta$-Sn grain is limited by the anisotropy of $\mathrm{Sn}$ crystal orientation which has a body-centered tetragonal crystal structure [21]. The deformation and destruction are effected by limited slip system. As a result, the fracture specimen of Sn-based solder occurs chisel-point easily. In the Sn-10Sb-0.10Ni and Sn-10Sb-0.50Ni fractured specimens, dimples and intergranular fracture were observed at the fracture surfaces at $25^{\circ} \mathrm{C}$. Sn- $10 \mathrm{Sb}-0.05 \mathrm{Ni}$ and $\mathrm{Sn}-10 \mathrm{Sb}-0.25 \mathrm{Ni}$ specimens also had a similar fractured surface. The intergranular fracture is the brittle fracture which the crack progress along a grain boundary. These specimens consisted of several grains as shown in the Figure 7, and thus the crack passed through the grain boundary on the way. At $150{ }^{\circ} \mathrm{C}$ and $200{ }^{\circ} \mathrm{C}$, chisel-point fractures were observed. The others also had a similar fracture surface. The $\beta$-Sn melting temperature is $232{ }^{\circ} \mathrm{C}$ and is considerably elongated and deformed at high temperature, therefore chisel-point fracture easily occurs.

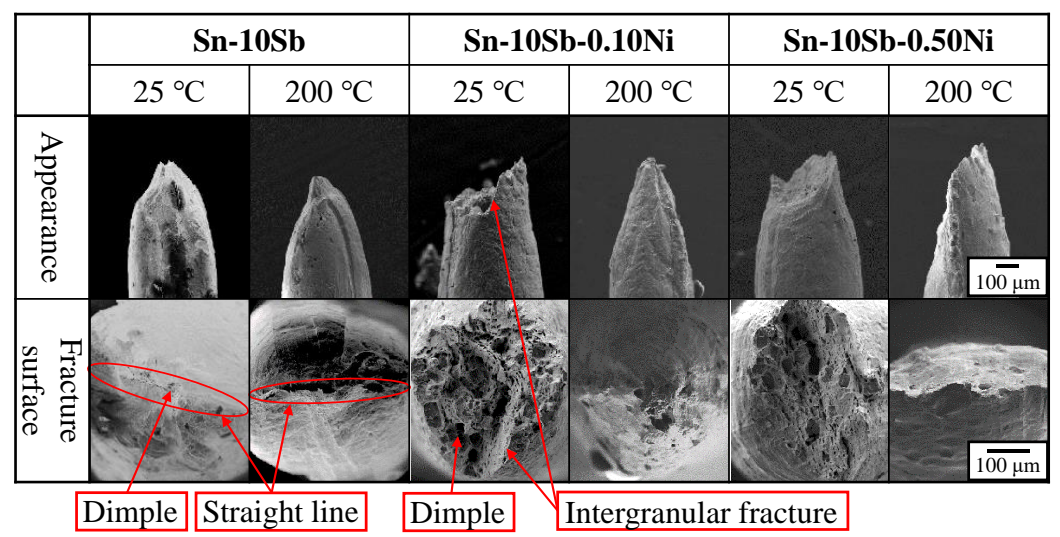

Figure 10. Secondary electron (SE) images of fractured specimens after tensile tests. 
Figure 11 shows the SE image and its EPMA mapping analysis result of the fractured surface of a Sn-10Sb-0.50Ni specimen after the test. In the image, a plurality of particles were observed in the dimples. From the EPMA mapping analysis result, the particles were inferred to be Sb-Sn and Ni-Sb compounds.

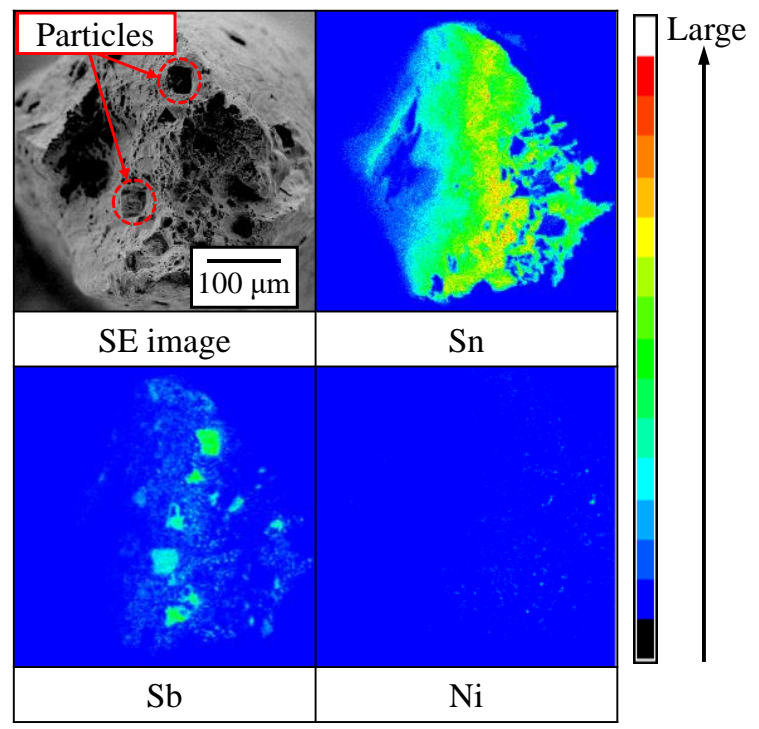

Figure 11. SE image of fractured surface of Sn-10Sb-0.50Ni and corresponding EPMA composition maps after tensile test (test temperature: $25^{\circ} \mathrm{C}$ ).

Figure 12 shows the schematic diagrams of the formation mechanism of the dimples and intergranular fracture. During tensile deformation of Sn-10Sb-Ni specimen, voids are generated between the $\mathrm{Sb}-\mathrm{Sn}$ and Ni-Sb compounds and the $\beta$-Sn matrix. This is because elastic modulus between the compounds and the matrix is different. Afterward, the voids become larger and combine each other, and eventually the specimen is broken. As a result, the dimples are formed on the fracture surface. If the specimen consists of several grains, crack passes through the grain boundary along the way. As a result, the intergranular fracture occurs.

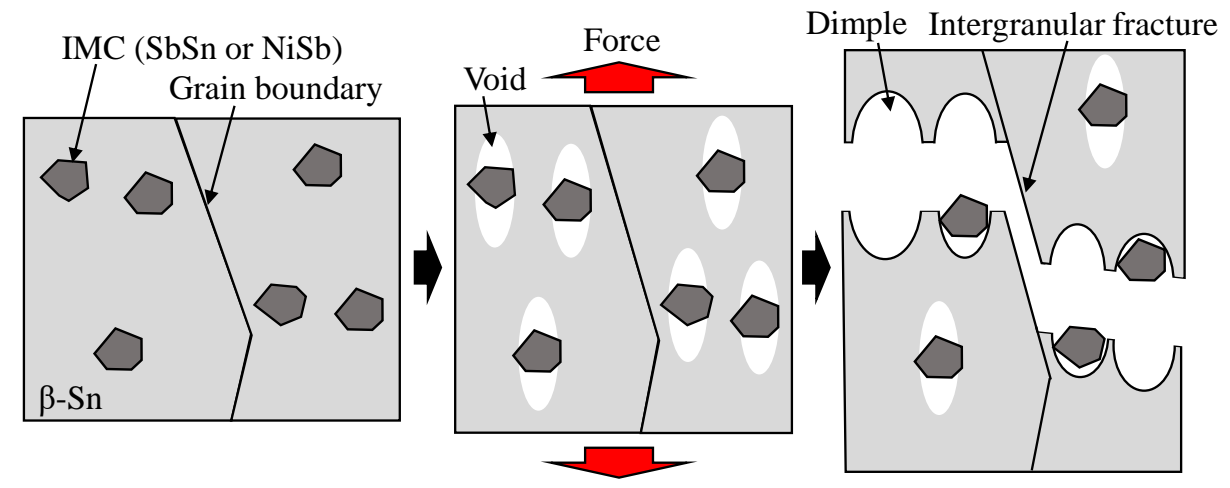

Figure 12. Schematic diagrams of formation mechanism of dimple and intergranular fracture.

\subsection{Fatigue Properties and Microstructural Change}

Figure 13 shows the relationship between the inelastic strain range and the number of cycles to failure of the Sn-10Sb and Sn-10Sb-Ni with $0.05-0.50$ mass $\%$ Ni specimens plotted on the double logarithm. In the graphs, Sn-10Sb and Sn-10Sb-Ni obey the Manson-Coffin equation as follows regardless of the temperature.

$$
C=\Delta \varepsilon_{\mathrm{in}} \cdot N_{\mathrm{f}}^{\alpha}
$$


where $C$ is the fatigue ductility factor, $\Delta \varepsilon_{\text {in }}$ is the inelastic strain range, $N_{\mathrm{f}}$ is the number of cycles to failure, and $\alpha$ is the fatigue ductility exponent. It has known that the low-cycle fatigue life of solder alloys generally obeys the Manson-Coffin equation [22-25].
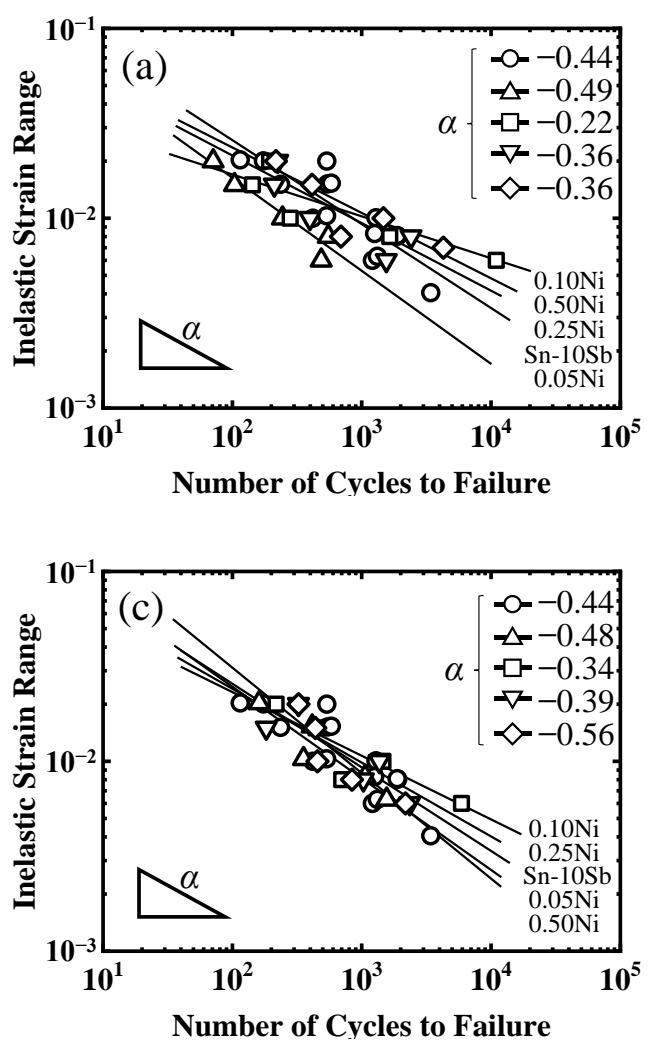

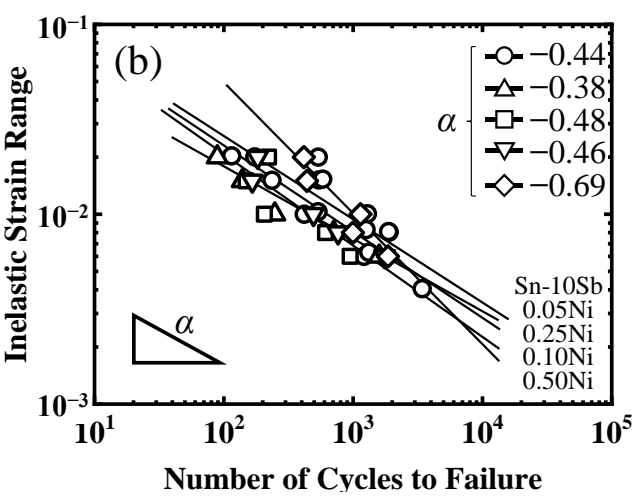

$$
\begin{aligned}
& -\mathrm{-Sn}-10 \mathrm{Sb} \\
& -\triangle \mathrm{Sn}-10 \mathrm{Sb}-0.05 \mathrm{Ni} \\
& \square-\mathrm{Sn}-10 \mathrm{Sb}-0.10 \mathrm{Ni} \\
& \nabla-\mathrm{Sn}-10 \mathrm{Sb}-0.25 \mathrm{Ni} \\
& \diamond \mathrm{Sn}-10 \mathrm{Sb}-0.50 \mathrm{Ni}
\end{aligned}
$$

Figure 13. Fatigue properties of Sn-10Sb and Sn-10Sb-Ni with $0.05-0.50$ mass $\%$ Ni. (a) $25^{\circ} \mathrm{C},(\mathbf{b}) 150{ }^{\circ} \mathrm{C}$, and (c) $200{ }^{\circ} \mathrm{C}$.

The $\alpha$ is a slope of a linear line in the double logarithmic graphs showing a relationship between the $\Delta \varepsilon_{\text {in }}$ and $N_{\mathrm{f}}$. The lower the absolute values of $\alpha$ becomes, the better the fatigue properties obtain. At $25^{\circ} \mathrm{C}$, the absolute values of $\alpha$ of the Sn-10Sb-Ni solder alloys except for $\mathrm{Sn}-10 \mathrm{Sb}-0.05 \mathrm{Ni}$ were smaller than that of the $\mathrm{Sn}-10 \mathrm{Sb}$. This means that these solder alloys have better fatigue properties than the $\mathrm{Sn}-10 \mathrm{Sb}$. The $\alpha$ values of the Sn- $10 \mathrm{Sb}-0.05 \mathrm{Ni}$ and $\mathrm{Sn}-10 \mathrm{Sb}$ were almost the same at $25^{\circ} \mathrm{C}$. At $150{ }^{\circ} \mathrm{C}$ and $200{ }^{\circ} \mathrm{C}$, the absolute values of $\alpha$ values of the Sn-10Sb-Ni solder alloys except for the Sn-10Sb-0.05Ni tended to increase. This result has the same tendency as the fatigue properties of $\mathrm{Sn}-5 \mathrm{Sb}-\mathrm{Ni}$ solder alloys that tested previously [16]. In particular, the absolute values of $\alpha$ of the Sn-10Sb-0.50Ni which has the most $\mathrm{Ni}$ addition was largest among all of the solder alloys in this study. The absolute values of $\alpha$ of the Sn-10Sb-0.05Ni were smaller than or almost the same to that of Sn- $10 \mathrm{Sb}$ at $150{ }^{\circ} \mathrm{C}$ and $20{ }^{\circ} \mathrm{C}$. Compared with the Sn-10Sb and Sn-10Sb-Ni, the absolute values of $\alpha$ of the Sn-10Sb-Ni with 0.05-0.25 mass\% Ni were smaller or almost the same to that of the Sn-10Sb at high temperature. In particular, the fatigue properties of $\mathrm{Sn}-10 \mathrm{Sb}-0.10 \mathrm{Ni}$ and $\mathrm{Sn}-10 \mathrm{Sb}-0.25 \mathrm{Ni}$ are superior to the $\mathrm{Sn}-10 \mathrm{Sb}$ at $200{ }^{\circ} \mathrm{C}$, which is the operating temperature of the next-generation power semiconductors.

Figure 14 shows the SE images and corresponding IPF maps of the cross-sectional views of Sn-10Sb-0.50Ni specimens after the tests at $25^{\circ} \mathrm{C}$ and $200{ }^{\circ} \mathrm{C}$. At $25^{\circ} \mathrm{C}$, a crack progress caused in a $\beta$-Sn grain. At $200^{\circ} \mathrm{C}$, the crack progress caused in fine crystal grain boundaries. It has been reported that local recrystallization process leads to the creation of fine $\beta$-Sn grains along a crack propagation path in the Sn-Ag-Cu solder alloys [26]. Therefore, it seems that the same phenomenon occurred in the Sn-Sb-Ni solder alloys. 


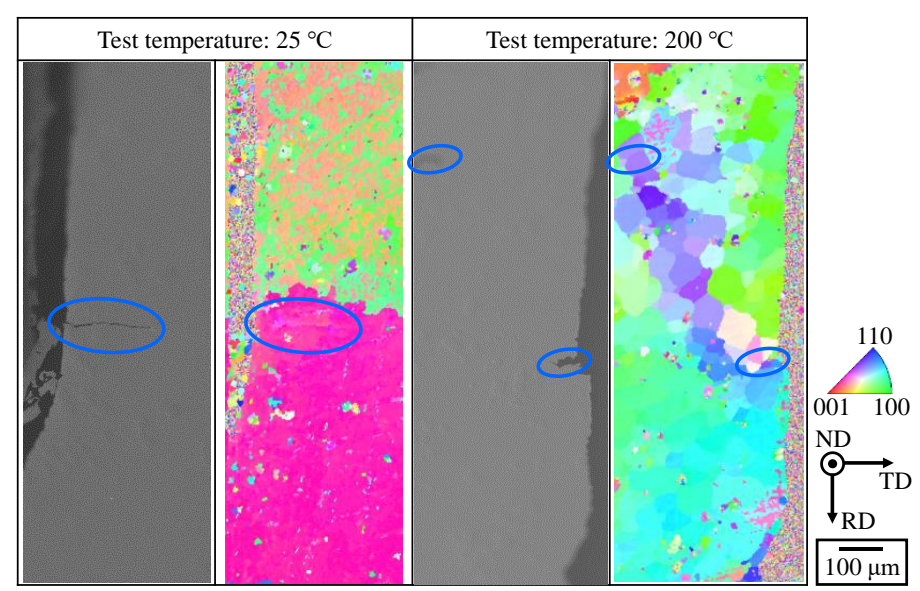

Figure 14. SE images and corresponding IPF maps of microstructures of Sn-10Sb-0.50Ni specimens after fatigue tests.

Figure 15 shows OM images of the microstructures of the cross-sectional views of the specimens after the tests. In the $\mathrm{Sn}-10 \mathrm{Sb}-0.05 \mathrm{Ni}$ specimen, the sub-micrometer size particles of Ni-Sb compounds were observed at $25^{\circ} \mathrm{C}$. In the $\mathrm{Sn}-10 \mathrm{Sb}-0.50 \mathrm{Ni}$ specimen, the $\mathrm{Ni}-\mathrm{Sb}$ compounds with $1-5$ micrometer and sub-micrometer sizes were observed at $25^{\circ} \mathrm{C}$. The fine and coarsened Sb-Sn compounds also exist in the both solder alloys. It has been reported that the fine dispersoids which are at Sn grains with can suppress $\mathrm{Sn}$ grain growth after recrystallization as the pinning effect for dislocations [27]. In this study, it appears that dispersed fine $\mathrm{Ni}-\mathrm{Sb}$ and $\mathrm{Sb}-\mathrm{Sn}$ compounds in the solder alloy have the pinning effect and suppress local recrystallization process at $25^{\circ} \mathrm{C}$. As indicated previously, as the $\mathrm{Ni}$ content in the $\mathrm{Sn}-10 \mathrm{Sb}-\mathrm{Ni}$ increases, the number of the $\mathrm{Ni}-\mathrm{Sb}$ compounds increases. Therefore, the $\mathrm{Sn}-10 \mathrm{Sb}-\mathrm{Ni}$ with the $\mathrm{Ni}$ amount of 0.10 mass $\%$ or more become small $\alpha$ values, and hence the solder alloys have superior fatigue properties at $25^{\circ} \mathrm{C}$. On the other hand, at $200^{\circ} \mathrm{C}$, the $\mathrm{Ni}$-Sb compounds are coarsened to more 10 micrometer sizes in the Sn-10Sb-0.50Ni. Furthermore, the Sb-Sn compounds are decomposed as shown in Figure 9. Consequently, the absolute values of $\alpha$ of the solder alloy increased and the fatigue properties deteriorated. It seems that the pinning effect decreases because of the coarsened $\mathrm{Ni}-\mathrm{Sb}$ compounds. Moreover, local recrystallization process is promoted due to deformation in the vicinity of the coarsened Ni-Sb compounds. In summary, it seems that the fatigue life decreased because the crack propagates easily to the fine $\beta$-Sn grain boundaries formed by local recrystallization process. On the other hand, in the $\mathrm{Sn}-10 \mathrm{Sb}-0.05 \mathrm{Ni}$, the fine $\mathrm{Ni}-\mathrm{Sb}$ compounds in the $\beta$-Sn matrix exist despite high temperature environment. Thus, stable fatigue properties can be obtained because local recrystallization process is suppressed.

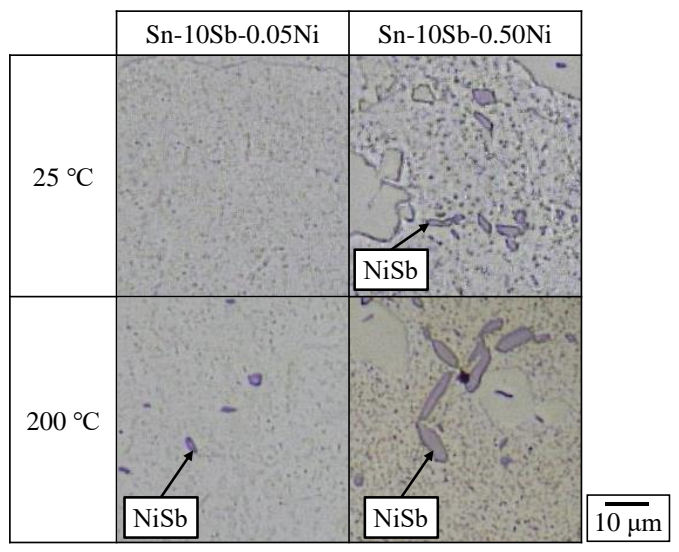

Figure 15. OM images of microstructures of Sn-10Sb-0.05Ni and Sn-10Sb-0.50Ni specimens after fatigue tests at $\Delta \varepsilon_{\mathrm{t}}=1.0 \%$. 


\section{Conclusions}

In this study, the microstructure and mechanical properties of Sn-10Sb-xNi solder alloys $(x=0.05$, $0.10,0.25,0.50$ mass $\%$ ) were investigated using miniature size specimens. The results of this study suggest the following conclusions:

(1) The Sn-10Sb-Ni solder alloys with $0.05-0.50$ mass $\%$ Ni have the microstructure in which $\mathrm{Sb}-\mathrm{Sn}$ and $\mathrm{Ni}-\mathrm{Sb}$ compounds are dispersed in $\beta$-Sn matrix. When $\mathrm{Sb}$ and $\mathrm{Ni}$ content in the $\mathrm{Sn}-\mathrm{Sb}-\mathrm{Ni}$ increases, the $\mathrm{Sb}-\mathrm{Sn}$ and $\mathrm{Ni}-\mathrm{Sb}$ compounds are coarsened, respectively.

(2) The effects of the Ni content on tensile properties of the Sn-10Sb-Ni solder alloys is slight at $25^{\circ} \mathrm{C}$. This is because the tensile properties are largely influenced by the dispersion of the coarsened SbSn compounds. At $150{ }^{\circ} \mathrm{C}$ and $200{ }^{\circ} \mathrm{C}$, the $0.1 \%$ proof stress and the tensile strength increase gradually with the Ni content increase, and saturate at the Ni amount over 0.25 mass $\%$. This is because the coarsened $\mathrm{Sb}-\mathrm{Sn}$ compounds decompose and $\mathrm{Ni}$-Sb compounds have a large effect on the tensile properties.

(3) The absolute values of the fatigue ductility exponents $\alpha$ of the Sn-10Sb-Ni solder alloys are smaller than that of the Sn-10Sb except for Sn-10Sb-0.05Ni at $25^{\circ} \mathrm{C}$. At $150^{\circ} \mathrm{C}$ and $200{ }^{\circ} \mathrm{C}$, the absolute values of $\alpha$ of all of the Sn-10Sb-Ni increase except for the Sn-10Sb-0.05Ni. In particular, the absolute values of $\alpha$ of the Sn-10Sb-Ni solder alloys are smaller than that of the Sn-10Sb except for $\mathrm{Sn}-10 \mathrm{Sb}-0.05 \mathrm{Ni}$ at $25^{\circ} \mathrm{C}$. The absolute values of $\alpha$ of the $\mathrm{Sn}-10 \mathrm{Sb}-0.50 \mathrm{Ni}$ are larger than any other solder alloys. Compared with the $\mathrm{Sn}-10 \mathrm{Sb}$ and $\mathrm{Sn}-10 \mathrm{Sb}-\mathrm{Ni}$, the fatigue properties of $\mathrm{Sn}-10 \mathrm{Sb}-\mathrm{Ni}$ solder alloys with $0.10-0.25$ mass $\% \mathrm{Ni}$ are better than that of Sn-10Sb at $200{ }^{\circ} \mathrm{C}$.

(4) In the $\mathrm{Sn}-10 \mathrm{Sb}-0.50 \mathrm{Ni}$ solder alloy, dispersed fine $\mathrm{Ni}-\mathrm{Sb}$ compounds have the dislocation pinning effect and suppress local recrystallization process at $25{ }^{\circ} \mathrm{C}$. However, at high temperature, the dislocation pinning effect decreases due to the formation of coarsened Ni-Sb compounds. Consequently, the fatigue life decreased because the crack propagates easily to the fine $\beta$-Sn grain boundaries formed by local recrystallization process.

Author Contributions: Conceptualization, T.K. and I.S.; methodology, I.S.; investigation, T.K.; data curation, T.K.; writing—original draft preparation, T.K.; writing—review and editing, T.K. and I.S.; supervision, I.S.

Funding: This research received no external funding.

Conflicts of Interest: The authors declare no conflict of interest.

\section{References}

1. Matallana, A.; Ibarra, E.; Lopez, I.; Andreu, J.; Garate, J.I.; Jorda, X.; Rebollo, J. Power module electronics in HEV/EV applications: New trends in wide-bandgap semiconductor technologies and design aspects. Renew. Sustain. Energy Rev. 2019, 113, 109264. [CrossRef]

2. Roccaforte, F.; Fiorenza, P.; Greco, G.; Nigro, R.L.; Giannazzo, F.; Iucolano, F.; Saggio, M. Emerging trends in wide band gap semiconductors ( $\mathrm{SiC}$ and $\mathrm{GaN}$ ) technology for power devices. Microelectron. Eng. 2018, 187-188, 66-77. [CrossRef]

3. Mu, F.; Wang, Y.; He, R.; Suga, T. Direct wafer bonding of GaN-SiC for high power GaN-on-SiC devices. Materialia 2018, 3, 12-14. [CrossRef]

4. Millan, J.; Godignon, P.; Perpina, X.; Perez-Tomas, A.; Rebollo, J. A survey of wide bandgap power semiconductor devices. IEEE Trans. Power Electron. 2014, 29, 2155-2163. [CrossRef]

5. Hayato, N.; Yuichiro, H.; Masafumi, H. Ultra-compact, high-reliability all-SiC module. Fuji Electr. Rev. 2013, 59, 221-225.

6. Suganuma, K.; Kim, S.J.; Kim, K.S. High-temperature lead-free solders: Properties and possibilities. JOM 2009, 61, 64-71. [CrossRef]

7. Kobayashi, K.; Shohji, I.; Hokazono, H. Tensile and fatigue properties of miniature size specimens of Sn-5Sb lead-free solder. Mater. Sci. Forum 2016, 879, 2377-2382. [CrossRef]

8. Rettenmayr, M.; Lambracht, P.; Kempf, B.; Graff, M. High melting Pb-free solder alloys for die-attach applications. Adv. Eng. Mater. 2005, 7, 965-969. [CrossRef] 
9. Dias, M.; Costa, T.; Rocha, O.; Spinelli, J.E.; Cheung, N.; Garcia, A. Interconnection of thermal parameters, microstructure and mechanical properties in directionally solidified Sn-Sb lead-free solder alloys. Mater. Charact. 2015, 106, 52-61. [CrossRef]

10. Chen, Y.T.; Chen, C.C. Interfacial reactions in Sn-Sb/Ni couples. J. Taiwan Inst. Chem. Eng. 2012, 43, 295-300. [CrossRef]

11. Lin, C.; Lee, C.; Liu, X.; Yen, Y. Phase equilibria of the Sn-Sb-Ag ternary system and interfacial reactions at the $\mathrm{Sn}-\mathrm{Sb} / \mathrm{Ag}$ joints at $400{ }^{\circ} \mathrm{C}$ and $150{ }^{\circ} \mathrm{C}$. Intermetallics 2018, 16, 230-238. [CrossRef]

12. Chen, S.W.; Zi, A.R.; Chen, P.Y.; Wu, H.J.; Chen, Y.K.; Wang, C.H. Interfacial reactions in the Sn-Sb/Ag and $\mathrm{Sn}-\mathrm{Sb} / \mathrm{Cu}$ couples. Mater. Chem. Phys. 2008, 111, 17-19. [CrossRef]

13. Chen, S.W.; Chen, C.C.; Gierlotka, W.; Zi, A.R.; Chen, P.Y.; Wu, H.J. Phase equilibria of the Sn-Sb binary system. J. Electron. Mater. 2008, 37, 992-1002. [CrossRef]

14. Corbin, S.F. High-temperature variable melting point $\mathrm{Sn}$-Sb lead-free solder pastes using transient liquid-phase powder processing. J. Electron. Mater. 2005, 34, 1016-1025. [CrossRef]

15. Kim, J.H.; Jeong, S.W.; Lee, H.M. Thermodynamics-aided alloy design and evaluation of Pb-free solders for high-temperature applications. Mater. Trans. 2002, 43, 1873-1878. [CrossRef]

16. Kobayashi, T.; Mitsui, K.; Shohji, I. Effects of Ni addition to Sn-5Sb high-temperature lead-free solder on its microstructure and mechanical properties. Mater. Trans. 2019, 60, 888-894. [CrossRef]

17. Kobayashi, T.; Kobayashi, K.; Mitsui, K.; Shohji, I. Comparison of Sn-5Sb and Sn-10Sb alloys in tensile and fatigue properties using miniature size specimens. Adv. Mater. Sci. Eng. 2018, 2018, 1416942. [CrossRef]

18. Morozumi, A.; Hokazono, H.; Nishimura, Y.; Mochizuki, E.; Takahashi, Y. Influence of antimony on reliability of solder joints using sn-sb binary alloy for power semiconductor modules. Trans. Jpn. Inst. Electron. Packag. 2015, 8, 8-17. [CrossRef]

19. Shohji, I.; Toyama, Y. Effect of strain rate on tensile properties of miniature size specimens of several lead-free alloys. Mater. Sci. Forum 2014, 783, 2810-2815. [CrossRef]

20. Kariya, Y.; Niimi, T.; Suga, T.; Otsuka, M. Isothermal fatigue properties of Sn-Ag-Cu alloy evaluated by micro size specimen. Mater. Trans. 2005, 46, 2309-2315. [CrossRef]

21. Telang, A.U.; Bieler, T.R. The orientation imaging microscopy of lead-free Sn-Ag solder joints. J. Miner. Met. Mater. Soc. 2005, 57, 44-49. [CrossRef]

22. Takahashi, H.; Kawakami, T.; Mukai, M.; Ohno, N. Thermal fatigue life simulation for Sn-Ag-Cu lead-free joints. J. Jpn. Inst. Electron. Packag. 2004, 7, 308-313. [CrossRef]

23. Kanchanomai, C.; Miyashita, Y.; Mutoh, Y. Low-cycle fatigue behavior of Sn-Ag, Sn-Ag-Cu, and Sn-Ag-Cu-Bi lead-free solders. J. Electron. Mater. 2002, 31, 456-465. [CrossRef]

24. Lee, C.C.; Chang, K.C. Lead-free solder joint reliability estimation of flip chip package using FEM-based sensitivity analysis. Solder. Surf. Mt. Technol. 2009, 21, 31-41. [CrossRef]

25. Pang, J.H.L.; Xiong, B.S.; Low, T.H. Low cycle fatigue study of lead free 99.3Sn-0.7Cu solder alloy. Int. J. Fatigue 2004, 26, 865-872. [CrossRef]

26. Libot, J.B.; Alexis, J.; Dalverny, O.; Arnaud, L.; Milesi, P.; Dulondel, F. Microstructural evolutions of Sn-3.0Ag-0.5Cu solder joints during thermal cycling. Microelectron. Reliab. 2018, 83, 64-76. [CrossRef]

27. Terashima, S.; Tanaka, M. Thermal fatigue properties of $\mathrm{Sn}-1.2 \mathrm{Ag}-0.5 \mathrm{Cu}-\mathrm{xNi}$ flip chip interconnects. Mater. Trans. 2004, 45, 681-688. [CrossRef]

(C) 2019 by the authors. Licensee MDPI, Basel, Switzerland. This article is an open access article distributed under the terms and conditions of the Creative Commons Attribution (CC BY) license (http://creativecommons.org/licenses/by/4.0/). 